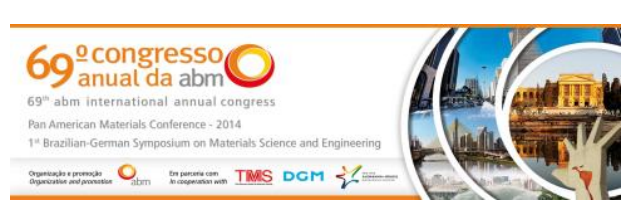

Theme: Physical Metallurgy and Materials Behavior at High Temperatures

\title{
EQUIVALENCE BETWEEN HOT TENSILE AND CREEP DATA IN ALUMINUM ALLOY AL7475-T7351. PART 1: RELATIONS INVOLVING STRESS, STRAIN RATE AND TEMPERATURE*
}

\author{
Diego José Inforzato ${ }^{1}$ \\ Gilmar Ferreira Batalha² \\ Erika Fernanda Prados ${ }^{3}$ \\ Levi de Oliveira Bueno ${ }^{4}$
}

\begin{abstract}
Hot tensile data were correlated with creep data, in Aluminum Alloy AL7475-T7351, as part of a broader research program, aiming at the validation of a methodology that proposes an equivalence between the two kind of results, for metallic materials in general. The methodology is based on a criterion that establishes correlation among the following parameters from each test: the strain rate, ultimate tensile stress, and time to reach the ultimate tensile stress, in tensile tests, are equivalent respectively to the: minimum strain rate, applied stress and rupture time, in creep tests, for a given test temperature. The present material was tested at 3 temperatures: 133,166 and $193^{\circ} \mathrm{C}$, using 3 nominal tensile strain rates in the hot tensile tests: $3.2 \times 10^{-6}, 1.6 \times 10^{-4}$ and $6.4 \times 10^{-3} \mathrm{~s}^{-1}$ and 9 applied stress levels in the creep tests, varying from 140 to $400 \mathrm{MPa}$. The conversion of the hot tensile data to creep-like data allowed performing the analysis of all the results together according to the traditional creep relations proposed by different authors, namely: Norton, Arrhenius, Zener-Hollomon and Monkman-Grant, with the determination of the corresponding parameters in each case. The equivalence between hot tensile and creep data is also confirmed for this aluminum alloy.
\end{abstract}

Keywords: Hot tensile data; Creep data; Alloy AL7475-T7351; Creep parameters.

1 MSc, Material Engineering, Structures-Materials, Embraer, São José dos Campos, SP, Brazil.

2 PhD, Mechanical Engineering, Associate Professor, Mech. Engineering, USP, São Paulo, SP, Brazil.

3 DSc, Materials Engineering, Pos-Doc Researcher, Mech. Engineering, USP, São Paulo, SP, Brazil.

$4 \mathrm{PhD}$, Materials Engineering, Associate Professor, Matls. Engineering, UFSCar, São Carlos, SP, Brazil.

* Technical contribution to the 69th $A B M$ International Annual Congress and to the ENEMET, July 21st-25th, 2014, São Paulo, SP, Brazil. 


\section{INTRODUCTION}

The possibility of correlating hot tensile data with creep data has been suggested in several publications, since 2004 [1-6]. In these first works only the $2.25 \mathrm{Cr}-1 \mathrm{Mo}$ steel was considered and extensively tested. A criterion was advanced [1] that establishes the rules for making the equivalence between the two kind of data, in the following way:

- The strain rate $(\dot{\varepsilon})$, the ultimate tensile stress (UTS) and the time to reach the ultimate tensile stress (tuts) in a hot tensile test is equivalent, respectively, to the minimum strain rate $\left(\dot{\varepsilon}_{\min }\right)$, the applied stress $(\sigma)$ and the rupture time $\left(\mathrm{t}_{\mathrm{r}}\right)$, in a creep test.

Figure 1 illustrates how the criterion must be applied the make the correspondence between tensile and creep results.

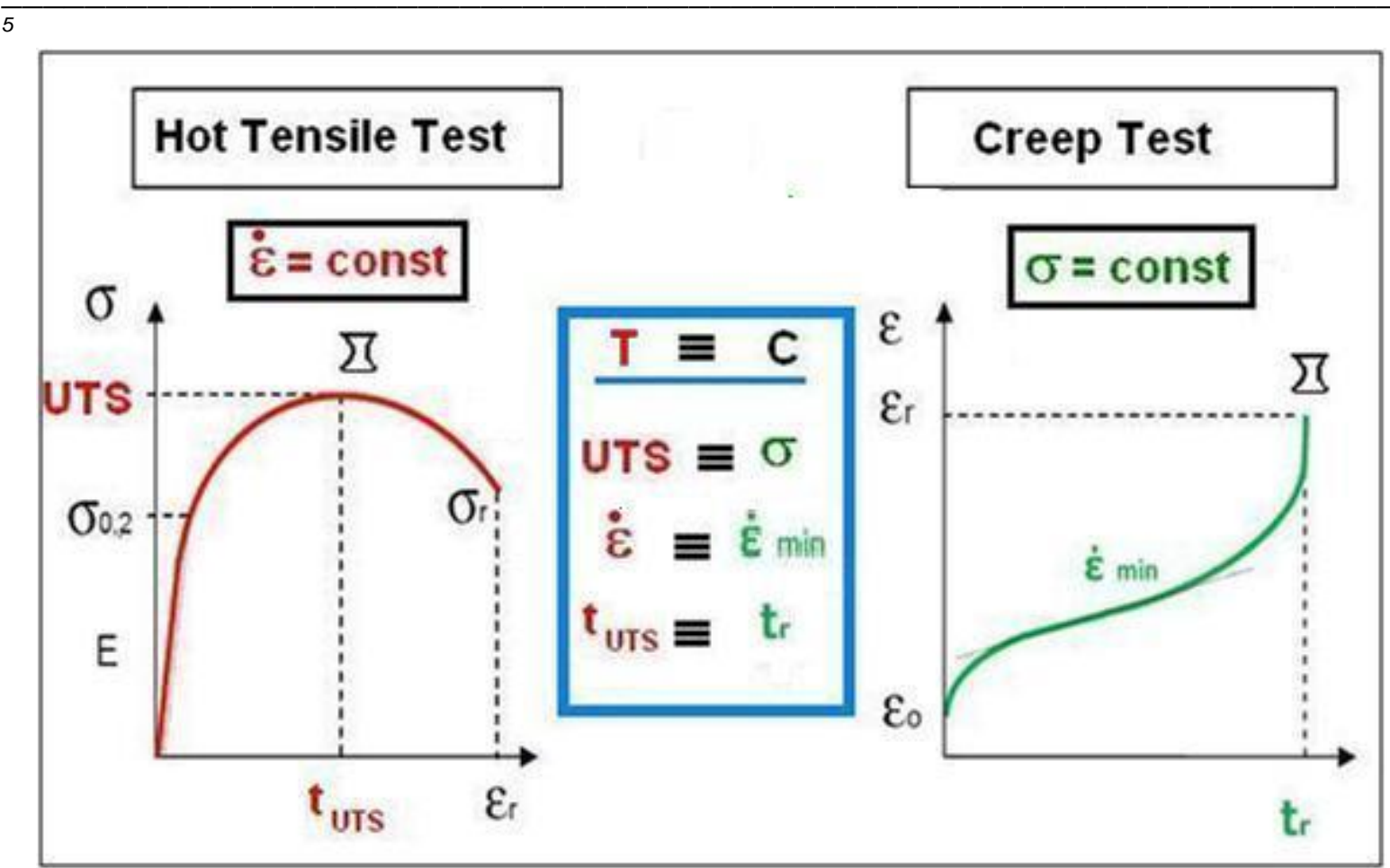

Figure 1. Schematic diagram illustrating the rules of equivalence between Hot Tensile data and Creep data, proposed by Bueno [1].

It is important to mention that in a tensile test, the value of $\dot{\varepsilon}$ is the independent variable, which is usually constant, and the values of UTS and tuTs are the dependent variables. On the other hand, in a creep test the value of $\sigma$ is the independent variable, which is usually constant, and the values of $\dot{\varepsilon}_{\text {min }}$ and $\operatorname{tr}$ are the dependent variables. Furthermore, in a tensile test, necking phenomenon starts just after the specimen reaches UTS, whilst in a creep test necking starts in the very last portion of tertiary stage.

The equivalence between both kinds of results was consistently confirmed for 2.25Cr-1Mo steel (1-6). Other kind of steels of the Cr-Mo type, as well as austenitic steels of the 300 series, refractory alloys (mainly of type $\mathrm{HP}+\mathrm{Nb}$ ), and even some superalloys were subjected to this methodology of analysis with excellent results. However, these works were produced as classified works, without possibility of publication yet. The applicability of the criterion of equivalence between hot tensile

\footnotetext{
* Technical contribution to the 69th $A B M$ International Annual Congress and to the ENEMET, July 215t-25th, 2014, São Paulo, SP, Brazil.
} 


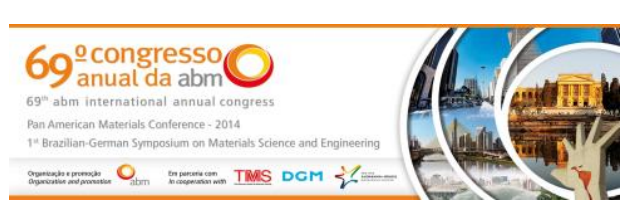

and creep data was tested with some non-ferrous materials, producing also remarkable results [7-12].

In the present article the methodology of equivalence is tested with a high strength aluminium alloy type AL7475-T7351. The hot tensile and creep data were not generated specifically for verifying the tensile/creep equivalence, but for application on a study of creep aging behavior of the material. The amount of data, specially from creep testing, was rather limited, but the methodology of equivalence could be applied satisfactorily. In this article, Part 1, both kind of results are analyzed together according to the traditional phenomenological and physical creep relations proposed in literature by different authors, namely: Norton, Arrhenius, Zener-Hollomon and Monkman-Grant, with the determination of the corresponding parameters in each case.

In Part 2 of this work, different parameterization methodologies for data extrapolation are also explored, to further test the reliability of the tensile/creep equivalence.

\section{MATERIAL AND METHODS}

AL7475 is basically a Al-1.5Cu-5.7Zn-2.2Mg-0.22Cr alloy. The material was supplied in the form of plate with $220 \times 220 \times 25(\mathrm{~mm})$ that was hot rolled and subjected to thermal treatment of type T7351. Specimens both for the hot tensile and creep tests were extracted from the rolling direction of the material and had the same shape and dimensions, as shown in Figure 2, i.e. they were flat with gauge-length $L O=45 \mathrm{~mm}$, cross-section with width $\mathrm{x}$ thickness of $8 \times 4 \mathrm{~mm}$.

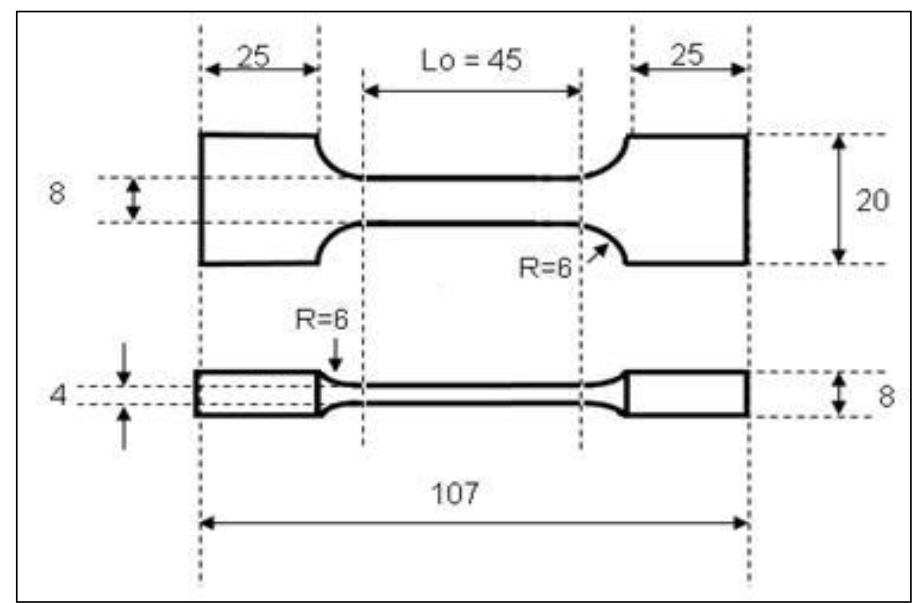

Figure 2. Schematic drawing illustrating the shape and dimensions of the hot tensile and creep specimens.

The hot tensile tests were carried out with an universal testing machine made by TIME Groups, model WDW 100E, with 10000 kgf capacity. The tests were performed at constant cross-head speed, without the use of extensometry localized in the gauge-length of the specimens, i.e. they were carried out at nominal constant strain rate. Three temperature levels were used: 133,163 and $193^{\circ} \mathrm{C}$. At each temperature level, three cross-head speeds were employed: $20,0.5$ and $0.01 \mathrm{~mm} / \mathrm{min}$. Altogether, 9 different tensile test conditions were explored.

The creep tests were carried out in creep machines made by STM, model STMMF/1000, with $1000 \mathrm{kgf}$ capacity. The tests were performed at constant load, with the use of extensometers employing LVDTs, connected to the grips and not directly to gauge-lengths of the specimens. Also three temperature levels were used: 133, 163 and $193^{\circ} \mathrm{C}$ and different levels of nominal applied stress were employed, namely:

* Technical contribution to the 69th ABM International Annual Congress and to the ENEMET, July 21st-25th, 2014, São Paulo, SP, Brazil. 
330,370 and $400 \mathrm{MPa}-$ at $133^{\circ} \mathrm{C}, 230,280$ and $310 \mathrm{MPa}-$ at $163^{\circ} \mathrm{C}, 140,190$ and $220 \mathrm{MPa}-$ at $193^{\circ} \mathrm{C}$. Also 9 different creep test conditions were explored with rupture times varying from about 4 min to $120 \mathrm{~h}$.

Hot Tensile and creep tests were carried out at homologous temperature of the order of $T_{h}=0.50$ to 0.57 .

To avoid confusion, and for more clarity, in the present article (and also in Part 2) the following nomenclature will be adopted for the variables involved in the two groups of test: a) the term Stress will be used in general, instead of Ultimate Tensile Stress in the hot tensile tests, and Stress applied in the creep tests; b) the term Strain Rate will be used in general, instead of Strain Rate applied in the hot tensile tests, and Minimum Creep Rate in the creep tests; c) the term Time will be used in general, instead of Time do reach the UTS in the hot tensile tests, and Rupture Time in the creep tests.

All values mentioned in this work for Stress, Strain and Strain Rate correspond to the nominal values and not the true values of these variables.

\section{RESULTS AND DISCUSSION}

Figure 3 shows the 9 Stress $\times$ Strain curves obtained from the hot tensile tests, and Figure 4 presents the 9 Strain $\times$ Time curves obtained from the creep tests. Tables 1 and 2 shows the main data values of the hot tensile tests and creep tests respectively. The sensitivity of the strength of the material with strain rate and temperature is highly evident in Figure 1.

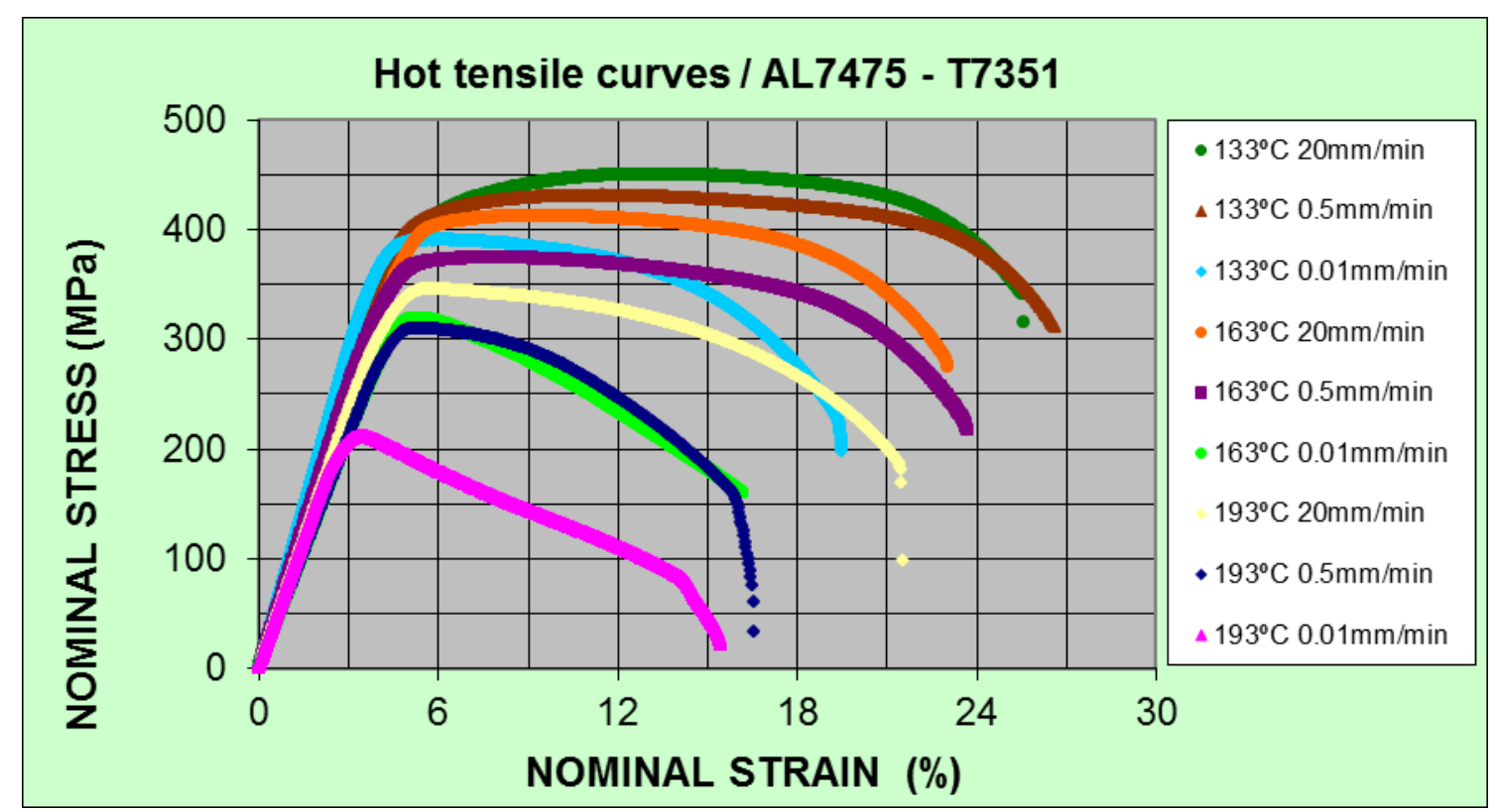

Figure 3. Hot Tensile curves at different cross-head speeds ( $20,0.5$ and $0.01 \mathrm{~mm} / \mathrm{min})$ and different temperatures $\left(133,163\right.$ and $\left.193^{\circ} \mathrm{C}\right)$. Obsv: nominal strain calculated directly from the displacement of the machine cross-head during the tests. 

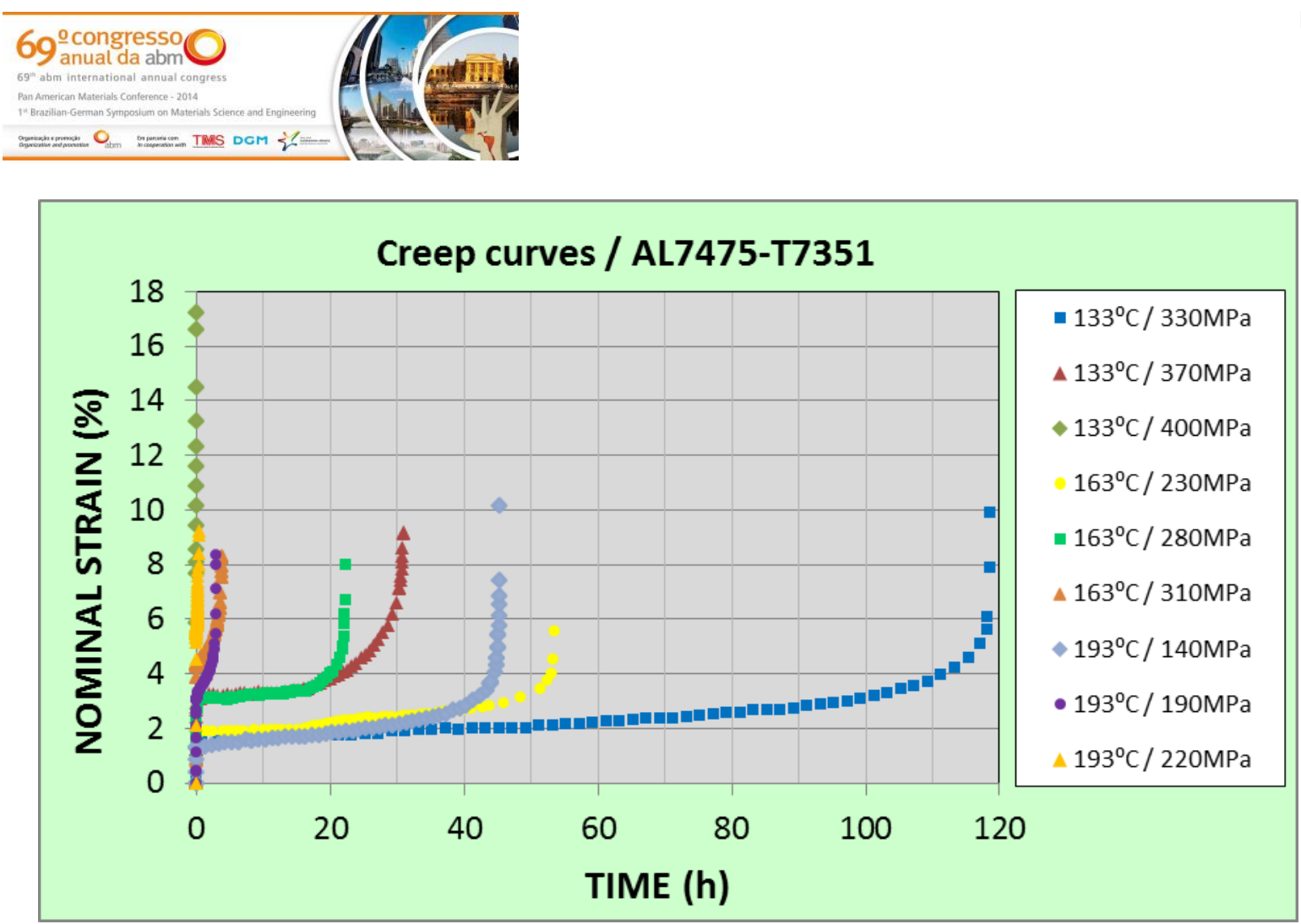

Figure 4. Creep curves at different applied stresses ( varying from 140 to $400 \mathrm{MPa}$ ) in different temperatures $\left(133,163\right.$ and $\left.193^{\circ} \mathrm{C}\right)$. Obsv: nominal strain calculated from extensometers attached to grips of the specimens; therefore, initial strain is not strictly equal the to gauge-length strain in the samples.

\begin{tabular}{|c|c|c|c|}
\hline \multicolumn{4}{|c|}{ TABLE 1 - HOT TENSILE DATA / AL7475-T7351 } \\
\hline & & & \\
\hline T ( & & & \\
\hline & UTS $(\mathrm{MPa})$ & $\dot{\varepsilon}\left(\% \mathbf{h}^{-1}\right)$ & t LRT (h) \\
\hline 133 & 451 & 2330.550 & 0.006 \\
\hline 133 & 431 & 58.050 & 0.199 \\
\hline 133 & 391 & 1.154 & 5.281 \\
\hline 163 & 413 & 2268.002 & 0.004 \\
\hline 163 & 375 & 56.433 & 0.138 \\
163 & 319 & 1.142 & 4.683 \\
\hline 193 & 346 & 2331.002 & 0.003 \\
\hline 193 & 310 & 58.640 & 0.093 \\
\hline 193 & 212 & 1.130 & 3.111 \\
\hline
\end{tabular}

\begin{tabular}{|c|c|c|c|}
\hline \multicolumn{4}{|c|}{ TABLE 2 - CREEP DATA / AL7475-T7351 } \\
\hline $\mathbf{T}\left({ }^{\circ} \mathrm{C}\right)$ & $\sigma(\mathrm{MPa})$ & $\dot{\varepsilon}_{\min }\left(\% \mathrm{~h}^{-1}\right)$ & $\operatorname{tr}(\mathrm{h})$ \\
\hline 133 & 330 & 0.008711 & 118.67 \\
\hline 133 & 370 & 0.0124 & 30.90 \\
133 & 400 & 104.4597 & 0.068 \\
\hline 163 & 230 & $0.0053 / 8$ & 53.50 \\
\hline 163 & 280 & 0.01998 & 22.27 \\
\hline 163 & 310 & 0.3389 & 3.80 \\
\hline 193 & 140 & 0.021742 & 45.34 \\
\hline 193 & 190 & 0.40296 & 3.02 \\
193 & 220 & 4.0180 & 0.35 \\
\hline
\end{tabular}

Figure 5 presents the variation of LOG(Stress) with LOG(Time) including the hot tensile and creep data. This graph is often referred to as the diagram of Loss of Creep Strength with Rupture Time in creep literature. Although the amount of data is limited in both cases, it can be noticed that the hot tensile results presents good compatibility with the creep results. In this figure (and the others subsequent) the letter T stands for Hot Tensile Test, and the letter $\mathrm{C}$ stands for Creep Test.

Figure 6 shows the hot tensile data and creep plotted together again in the form of a Norton diagram: LOG(Strain Rate) versus LOG(Stress). This kind of diagram is used when attempt is made to verify the validity of Norton relation: $\quad \dot{\varepsilon}_{\min }=A$. $\sigma^{n}$. As the creep tests were of relative short duration (high stresses) they are in fact near the region where creep changes from the potential to the exponential creep relation. The hot tensile data, involving still higher levels of stress, are certainly mostly in the exponential creep region. Figure 6 includes labels with the values of the Norton exponent, $\mathbf{n}$, at the edges of the stress ranges of each temperature level. At $133^{\circ} \mathrm{C}, \mathrm{n}$ changes drastically from 9.5 to 35 , at $163^{\circ} \mathrm{C}$ it changes from 17 to 45 and at $193^{\circ} \mathrm{C}$

\footnotetext{
* Technical contribution to the 69th ABM International Annual Congress and to the ENEMET, July 21st-25th, 2014, São Paulo, SP, Brazil.
} 
from 35 to 82 . In this figure, it is also evident the good compatibility that the hot tensile results presents with the creep results.

Due to the limited amount planned for creep tests, it was impossible to perform them in constant stress conditions, what would be essential for investigating the creep activation values of the material, through the Arrhenius relation: $\dot{\varepsilon}_{\min }=A^{\prime} \cdot \exp \left(-Q_{c} / R T\right)$. Using the curves fitted to the data in Figure 5, however, it was possible to make an estimation of the LOG(Strain Rate) values for the following stress levels: $398 \mathrm{MPa}$ $(\mathrm{LOG}(\mathrm{tr}) \approx 2.6), 316 \mathrm{MPa}(\mathrm{LOG}(\mathrm{tr}) \approx 2.5)$ and $251 \mathrm{MPa}(\mathrm{LOG}(\mathrm{tr}) \approx 2.4)$. With this data, it was possible to plot an Arrhenius type diagram containing 3 iso-stress lines, as shown in Figure 7, which produced an estimative of the Apparent Creep Activation value for the material, $Q_{c}=333 \mathrm{~kJ} / \mathrm{mol}$. For commercially pure aluminium, type AA1100 with $99 \%$ purity, a value of $Q_{c}=212 \mathrm{~kJ} / \mathrm{mol}$ was obtained [9]. Both values are considerably higher than those reported by Frost and Ashby [13] for extra-pure aluminium, $Q_{c}=142 \mathrm{~kJ} / \mathrm{mol}$. Creep data in this material however was obtained in a region where $\mathbf{n}$ varied from 4 to 5 , according to the authors[13]. The present material, being a high strength aluminium alloy with a complex pattern of precipitation, will certainly have a much higher creep activation energy than pure aluminium material.

Figure 8 presents the rationalization of the data shown in Figure 6, using in the $\mathrm{Y}$ axis the Zener-Hollomon parameter, $Z=\dot{\varepsilon}_{\min } . \exp \left(Q_{c} / R T\right)$, with $Q_{c}=333 \mathrm{~kJ} / \mathrm{mol}$. It is noticed that all the data from the different temperature levels collapse reasonably well into a single reference curve.

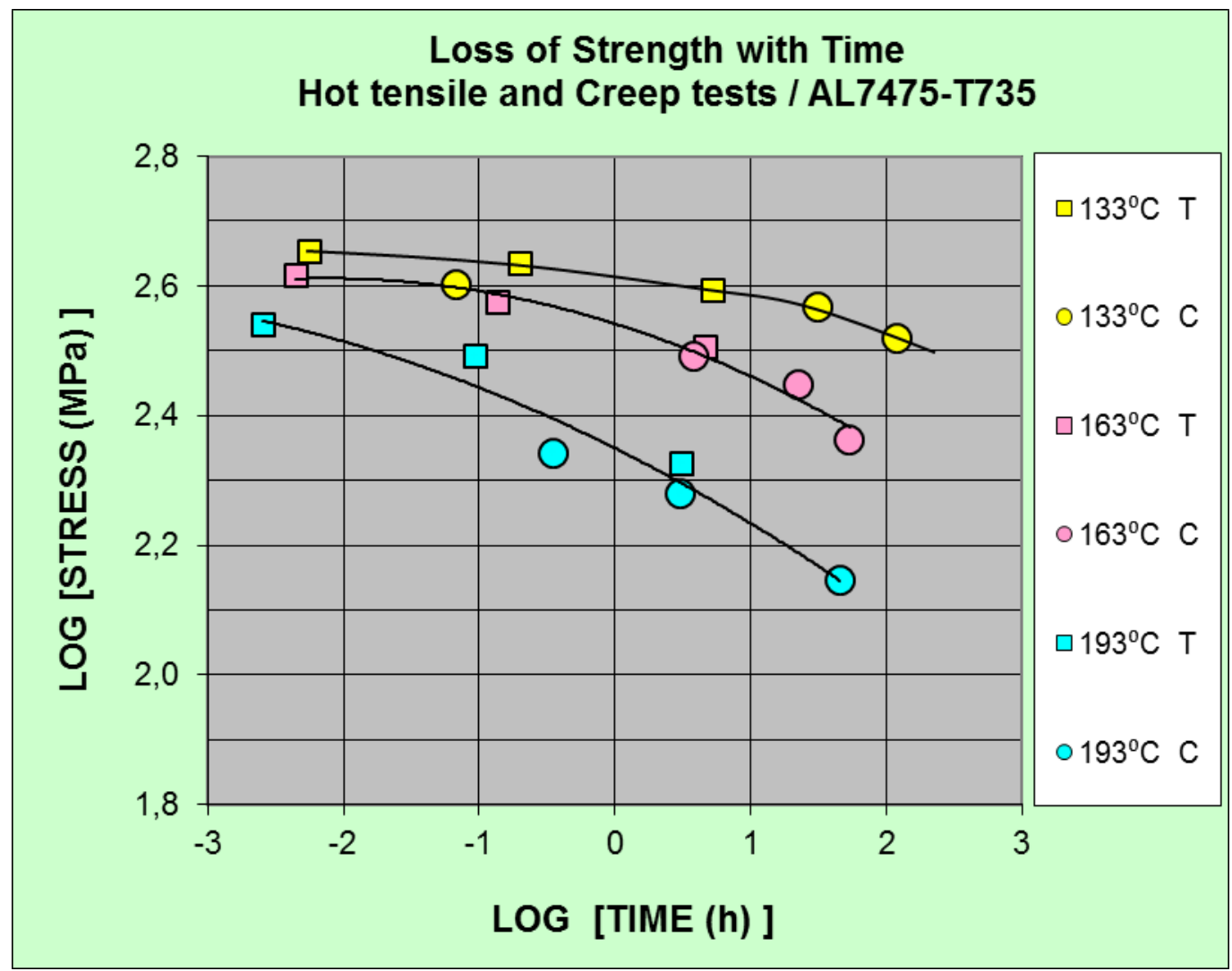

Figure 5. Loss of Strength with Time. 


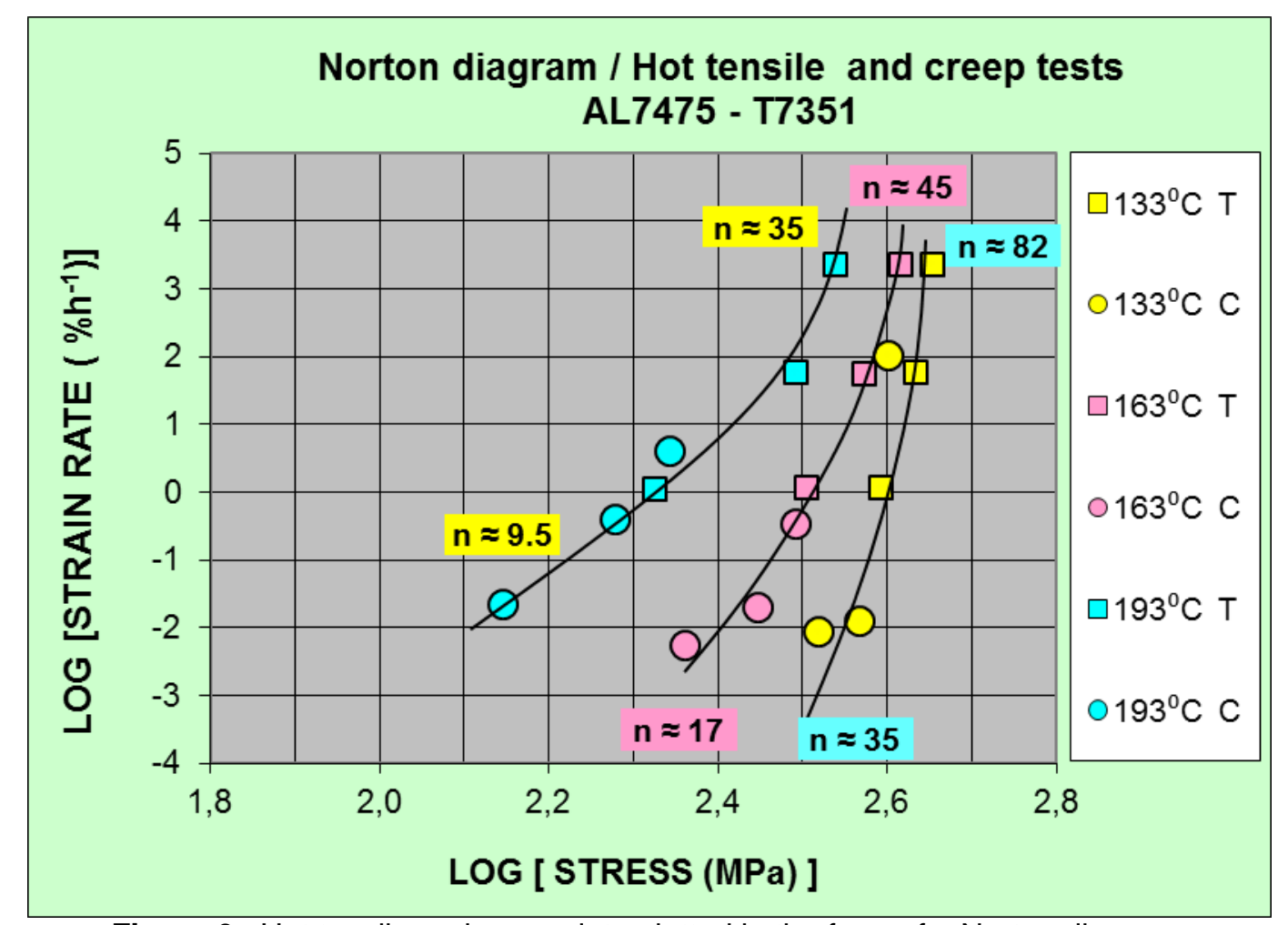

Figure 6. Hot tensile and creep data plotted in the form of a Norton diagram.

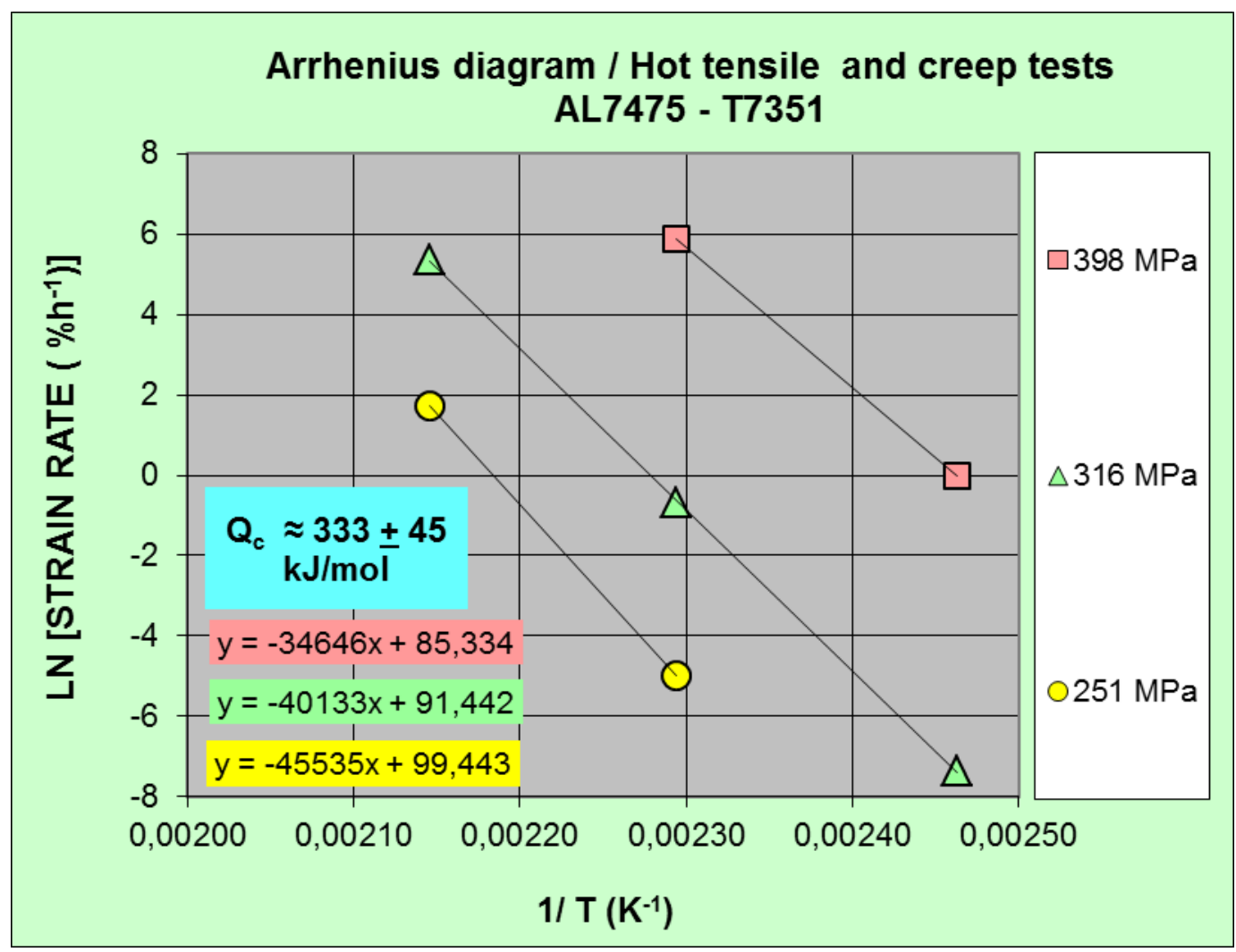

Figure 7. Arrhenius diagram for Hot Tensile and Creep results. 


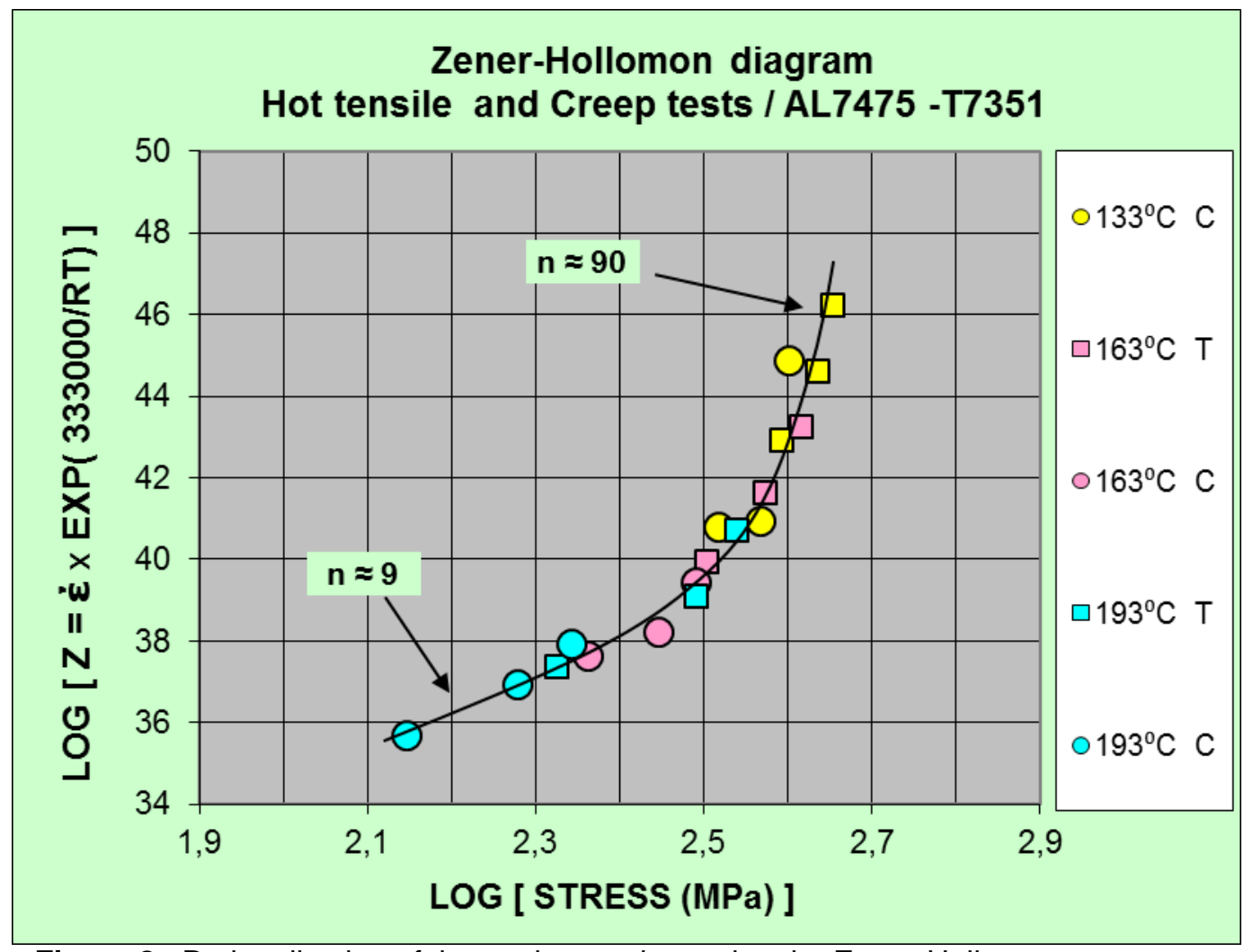

Figure 8. Rationalization of the strain rate data using the Zener-Hollomon parameter.

The regions in the extremity of this curve exhibits $\mathbf{n}$ values varying from $\mathbf{n} \approx 9$ (in the lowest stress range) to $\mathbf{n} \approx 90$ (in the highest stress range), which agree well with the lowest and highest values of $\mathbf{n}$ mentioned in Figure 6, respectively for $193^{\circ} \mathrm{C}$ and $133^{\circ} \mathrm{C}$. The increase in $\mathbf{n}$ values with increase in stress is widely known in literature, even when creep happens only in the potential region [14]. The correspondence of the hot tensile data with the creep data in Figure 8 can be considered also excellent.

Figure 9 presents the hot tensile and creep data plotted in the form of LOG(Strain Rate) versus LOG(Time), i.e. in the form of a Monkman-Grant diagram, used to verify the validity of the relation: $\dot{\varepsilon}_{\min } . \mathrm{tr}_{\mathrm{r}}{ }^{\mathrm{m}}=\mathrm{K}$. It is seen that all points in this diagram are grouped well around a unique straight line with reasonable value of linear correlation, having the following parameters: $m=1.2899$ and $\mathrm{K}=2.6080$. For $\mathrm{Cr}-\mathrm{Mo}$ steels[1-6], the values of $m$ are found to be very near to $m=1$, original value proposed for Monkman-Grant, which simplifies their expression to: $\dot{\varepsilon}_{\min } . \mathrm{t}_{\mathrm{r}}=\mathrm{C}$.

When hot tensile data are considered alone, they are usually plotted as LOG(Stress) versus $L O G(Z)$, instead of $L O G(Z)$ versus $L O G($ Stress) as shown in Figure 8. A plot like that is usually used to derive the values of the exponent of strain rate sensitivity of the material, m', according to the expression: $\sigma=C^{\prime} \varepsilon^{\prime} m^{\prime}[15]$. Figure 10 shows the hot tensile and creep data plotted in that way, where it can be noticed that the values of the strain rate sensitivity exponent varies from $m^{\prime} \approx 0.11$, at the lowest stress level, to $m^{\prime} \approx 0.011$, at the highest stress level. It is also notorious that $n=1 / \mathbf{m}^{\prime}$, i.e. the Norton exponent corresponds to the inverse of the strain rate sensitivity exponent. This correspondence can be verified in a natural way when the criterion of equivalence [1] proposed for analyzing of both kind of results together is adopted.

The data presented in Figure 10 also produces a best curve fitting in the form of a $3^{\text {rd }}$ degree polynomial, as shown in the label inserted in the figure, which can be used for testing the capability of the Zener-Hollomon parameter in expressing the present 
strain rate results. Figure 11 corresponds to the same diagram presented in Figure 6 , this time, however, showing the iso-temperature lines calculated with the ZenerHollomon methodology. It can be observed that the procedure is able to express quite satisfactorily both the hot tensile data as well the creep data obtained in this work. Care should be taken, however, in the use of such procedure for extrapolation of data much beyond the range of the experimental data.

A procedure similar to Bueno's methodology [1] was proposed by Steen [16] about 30 years ago to relate stress and strain rate data from hot tensile and creep testing. However, this author did not mention any time parameter from the hot tensile test corresponding to rupture time in a creep test. It is important to mention also the work reported by Osgerby and Dyson [17] about 20 years ago, which establishes an almost identical procedure for comparing both kind of data, also in terms of stress and strain rate only. The work of these authors [11] is important by the fact that their approach is supported by a physical model using mechanisms-based equations for creep behavior. With their model it seems possible to predict stress trajectories as a function of strain under constant strain rate.

According to these authors, primary, secondary and tertiary creep behavior can be described by the following equation:

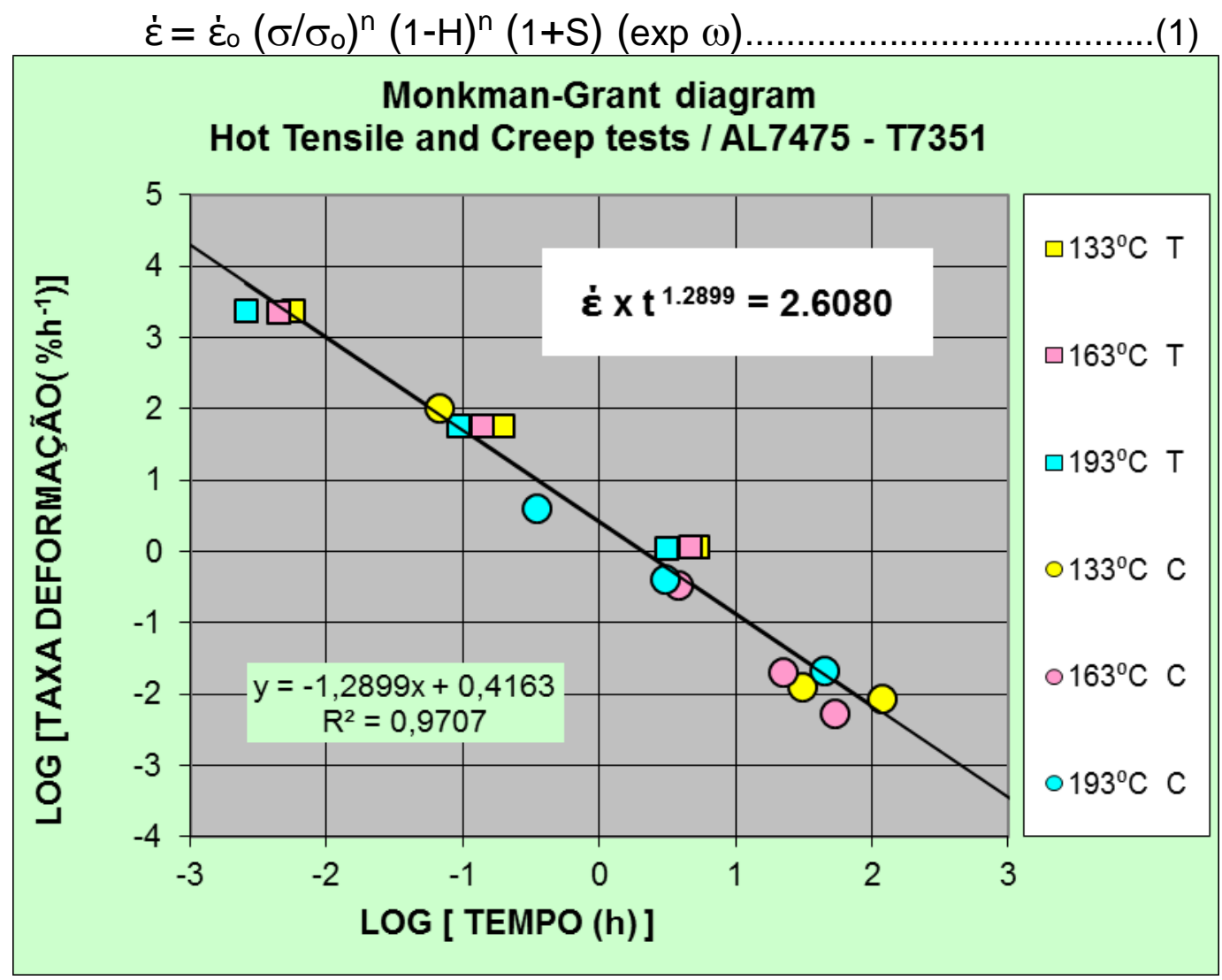

Figure 9. Monkman-Grant diagram for the Hot Tensile and Creep data. 


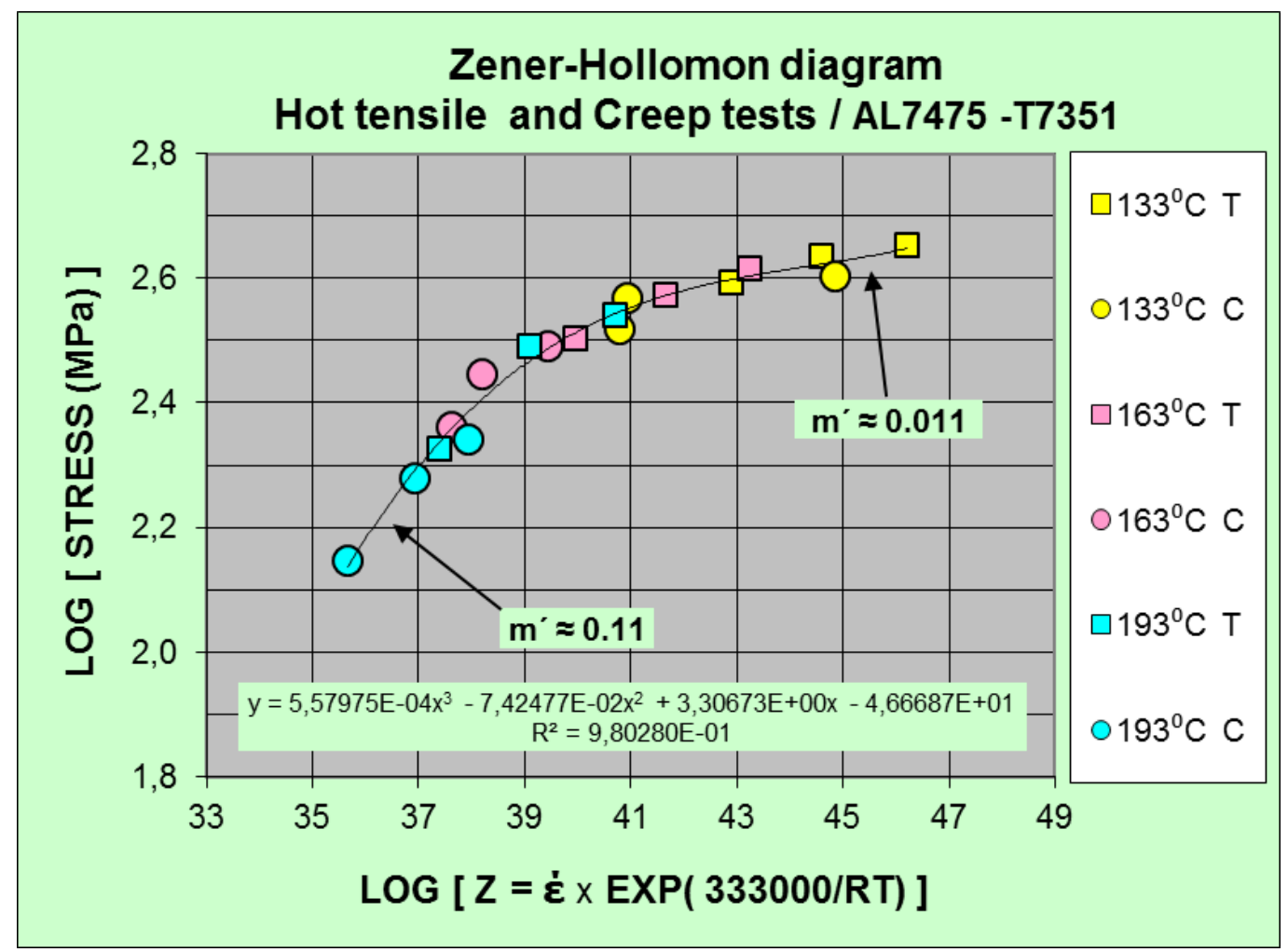

Figure 10. Strength of the material expressed in terms of the Zener-Hollomon parameter: a better option for curve fitting using a $3^{\text {rd }}$ degree polynomial.

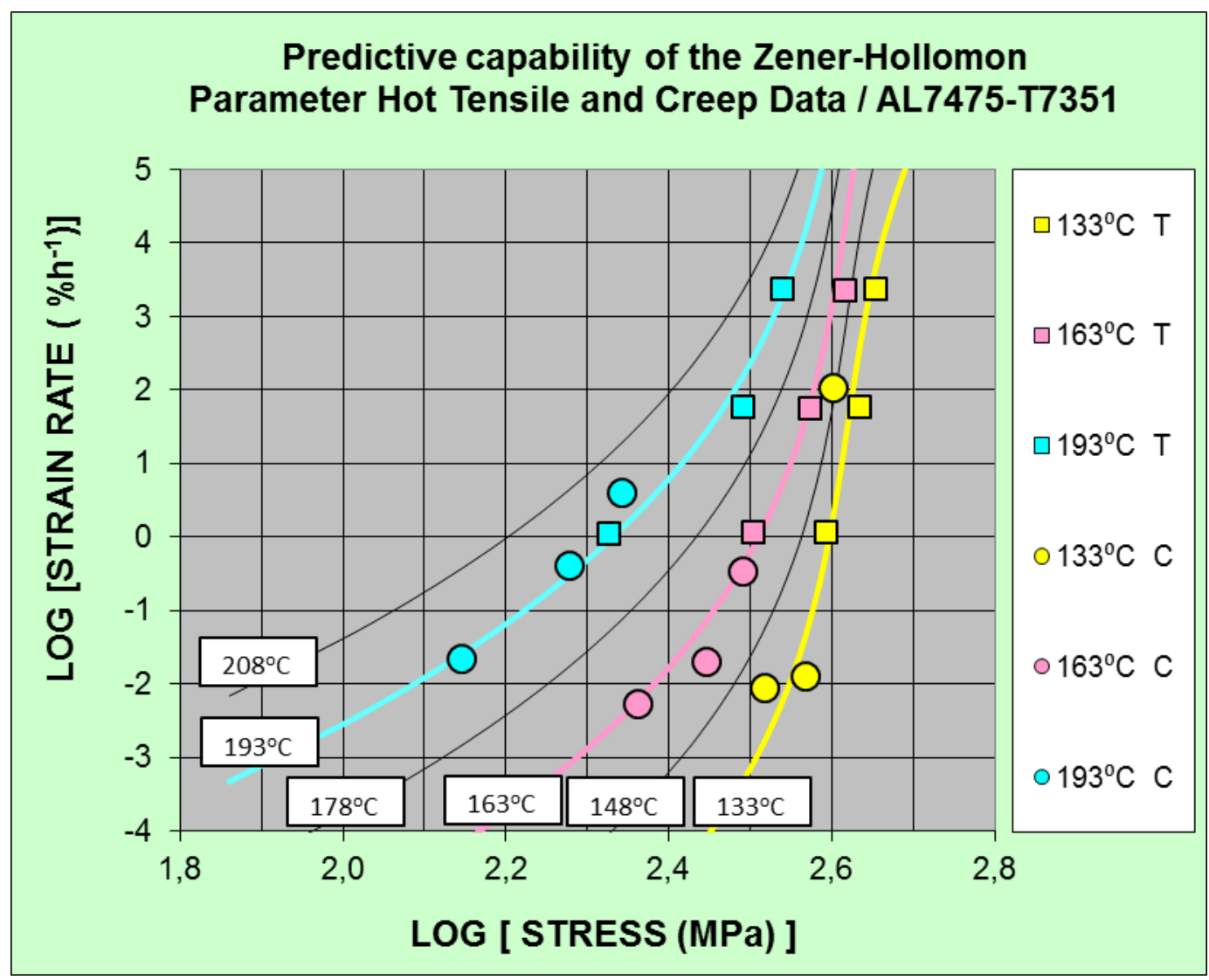

Figure 11. Predictive capability of the Zener-Hollomon parameterization in expressing the variation of strain rate with stress. 
with

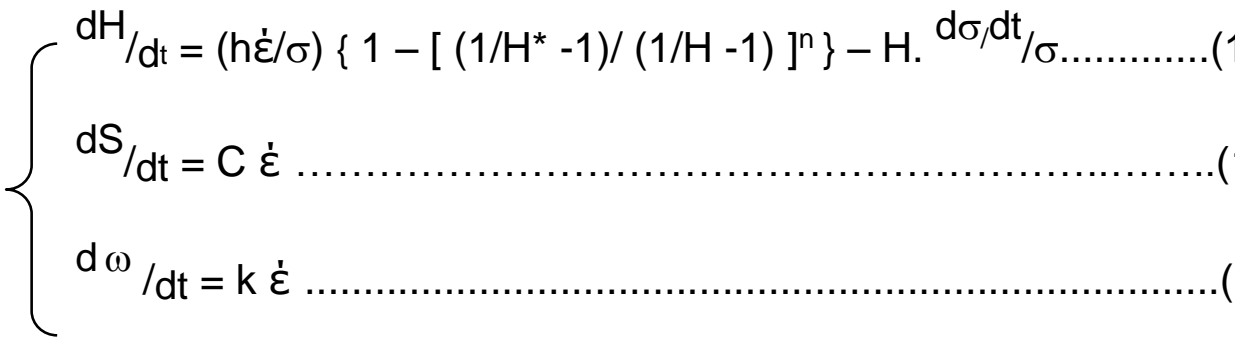

$\dot{\boldsymbol{\varepsilon}}_{\mathrm{o}}$ is the initial creep rate of the material under the action of an applied stress $\sigma_{\mathbf{o}} ; \mathbf{n}$ is the creep stress exponent; $\mathbf{H}$ is a normalized internal stress, leading to primary creep, which has a saturation value $\mathbf{H}^{\star}$ and a hardening coefficient $\mathbf{h}$; $\mathbf{S}$ is a parameter describing tertiary creep due to dislocation softening and having an associated coefficient $\mathbf{C}$; $\boldsymbol{\omega}$ is a parameter describing tertiary creep due to intergranular cavitation, having an associated coefficient $\mathbf{k}$ of magnitude $\mathbf{n} / 3 \boldsymbol{\varepsilon}_{\mathbf{f}}$, where $\boldsymbol{\varepsilon}_{\mathfrak{f}}$ is the uniaxial strain to failure.

A suggestion was put forward by Steen [16] that constant strain rate data could be used as convenient substitute for the time-consuming creep results. Contrary to Steen[16], however, Osgerby and Dyson [17] consider exactly an opposite position, i.e. that creep testing can substitute hot tensile testing economically in many situations by the use of cheaper kind of equipment, spending lower testing times. In fact, it seems quite inadequate to use an expensive constant crosshead speed machine for high temperature tests to generate data of longer durations in the creep region.

Both Steen [16] and Osgerby and Dyson [17] envisaged the correlation only between strain rate and stress for tensile and creep testing in the same manner of this work, i.e., as expressed in the criterion [1] presented in the Introduction of this article. However, both of them, did not mention the possibility of finding and equivalent for rupture time in the strain rate tests, as expressed in rule of the criterion [1] that states that: $t_{r}=$ tuts.

A more detailed discussion about this aspect was presented by Bueno some time ago [4].

The present criterion was developed mainly on basis of experimental observation and if its validity is confirmed it should be supported by an appropriate physical theory. The work of Osgerby and Dyson [17] seems to provide the necessary mechanistic equations for confirming the correlation between hot tensile and creep testing, according to the present criterion.

A procedure for determining the rupture time and creep strain rate from uniaxial tensile test was proposed by Oh [18], a few years after Osgerby and Dyson [17]. In this work, the author envisaged the correlation of UTS with applied creep stress and time of uniform elongation in tensile test (tuts) with rupture time in the same way as proposed by Bueno [1]. However they suggested the use of only one hot tensile test result carried out at a certain temperature with a single strain rate to predict the rupture time and minimum creep rate at this temperature, using the Larson-Miller parameter, with $\mathrm{C}=20$. The procedure is in fact a simplification of the methodology of analysis used in this article.

More recently, a correlation for hot tensile testing with creep testing was proposed by Goldenberg [19], based on phenomenological and statistical-thermodynamics equations assumed as valid for both phenomena. This author states clearly, however, that his exponential equations can be used for predicting long term creep rupture times and strength from short time tensile tests at temperature of more than $2 / 3$ of the melting temperature and that they are related to one physical mechanism

* Technical contribution to the 69th $A B M$ International Annual Congress and to the ENEMET, July 215t-25th, 2014, São Paulo, SP, Brazil. 


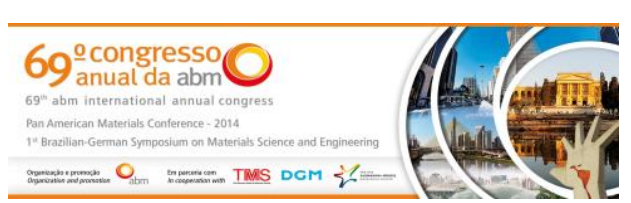

operating for both short- and long-term lives at this temperature. Over the last 60 years $[13,20]$ it has been well established that creep happens under the control of many mechanisms, and rarely under one single mechanism with a unique activation energy and simple exponential equations for stress and rupture time. Furthermore, creep phenomenon happens and is technically important for metals at temperatures greater than $1 / 3$ of the melting temperature. When that theory [18] is applied in practice, as done by Chen et al [21], it predicts, for instance, that the iso-temperature data in a plot of LOG (Stress) with LOG (Rupture Time) are represented by parallel straight lines, which is clearly not the case for creep behavior of metallic materials in general, as shown in Figure 5, for AL7475-T7351.

Recently, a comparison was made by Sreenivasan [22] between the procedure of Oh [18] and the methodology of Bueno [1] for determining rupture times and creep rates for AISI 316L steel. The author concluded that Oh [18] procedure gives creep rates much larger (and much shorter rupture times) compared to the real ones, being therefore very conservative results. According to this author [18] the methodology suggested by Bueno [1] is more laborious but more reliable to generate better results.

\section{CONCLUSION}

The results obtained for the correlation between hot tensile data and creep data for AL7475-T7351, according to the methodology of equivalence between them [1], were highly satisfactory. As verified previously for other metallic materials [1-12], the criterion proposed for equivalence between both kinds of results, worked well also for this high strength aluminium alloy.

In the various situations involving correlation among variables such as Strain Rate, Time, Stress and Temperature, the proposed methodology enabled the use of a unique procedure of analysis for the hot tensile data together with the creep data, according to the main relations of proposed by various authors in the past for the analysis of creep phenomenology: Norton, Arrhenius, Zener-Hollomon and Monkman-Grant, with the determination of their respective parameters in each case.

\section{Acknowledgments}

The authors acknowledges EMBRAER for giving permission for publication of this article.

\section{REFERENCES}

1 Bueno LO. Creep Behaviour of 2.25Cr-1Mo Steel - An equivalence between Hot Tensile and Creep testing data. ECCC Creep Conference, 12-14 September 2005, London Proc. Creep \& Fracture in High Temperature Components - Design and Life Assessment Issues - Edited by: I.A.Shibli, S.R.Holdsworth, G.Merckling. DEStech Publ., USA. 2005; 969-980.

2 Bueno LO. A simple criterion for converting hot tensile data to creep data and viceversa. Proc. $8^{\text {th }}$.International Colloquium on Ageing of Materials and Methods for the Assessment of Lifetimes of Engineering Plant. Gordon's Bay, South Africa, 7-11 March 2005. EMAS Publishing Ltd. 2005;103-117.

3 Reis Sobrinho JF, Bueno LO. Correlation between Creep and Hot Tensile Behavior for 2.25Cr-1Mo Steel from $500^{\circ} \mathrm{C}$ to $700^{\circ} \mathrm{C}$. Part 2: An Assessment According to Different Parameterization Methodologies. Revista Matéria. 2005; 10-3: 463 - 471.

\footnotetext{
* Technical contribution to the 69th ABM International Annual Congress and to the ENEMET, July $21^{s t}-25^{\text {th }}$, 2014, São Paulo, SP, Brazil.
} 


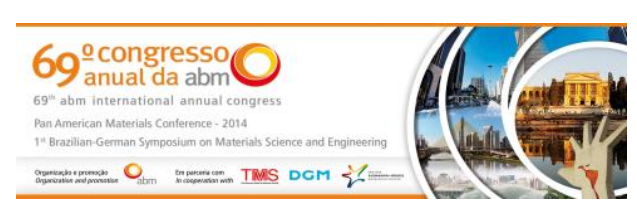

4 Bueno LO. On the Equivalence between Hot Tensile and Creep data. Proc. $61^{\text {st }}$ Intl. Conf. of ABM, 24-27 July 2006, Rio de Janeiro(RJ),Brazil. 2006; CDROM: 2245-2258.

5 Bueno LO, Reis Sobrinho JF. Correlation Between Creep and Hot Tensile Behavior for $2.25 \mathrm{Cr}-1 \mathrm{Mo}$ Steel from $500^{\circ} \mathrm{C}$ to $700^{\circ} \mathrm{C}$. Part 1: An Assessment According to usual relations involving Stress, Temperature, Strain Rate and Rupture Time. Revista Matéria. 2012; 17-3: 1098 - 1108.

6 Santos NB, Reis Sobrinho JF, Bueno LO. Equivalência entre dados de Tração a Quente e Fluência no aço 2,25Cr-1Mo. Parte 1 - Ampliação da base de dados na faixa de 500 a $700^{\circ}$ C. Proc. 68 ${ }^{\text {th }}$. Intl. Conf. of ABM, 30/7-02/8 August 2013, Belo Horizonte(MG),Brazil. 2013; CDROM:

7 Dias CRF, Bueno LO. Correlação Tração a Quente e Fluência para o Cobre Comercial Puro. Parte 1: Relações entre Tensão, Taxa de Deformação, Tempo de Ruptura e Temperatura. Proc. $65^{\text {th }}$ Annual Congress of ABM, July 2010, Rio de Janeiro(RJ), Brazil. 2010; CDROM: 1253 - 1263.

8 Bueno LO, Dias CRF. Correlação Tração a Quente e Fluência para o Cobre Comercial Puro. Parte 2: Análise por diferentes Metodologias de Parametrização. Proc. $65^{\text {th }}$ Annual Congress of ABM, July 2010, Rio de Janeiro(RJ), Brazil. 2010; CDROM: 1264 - 1274. Also in Tecnologia em Metalurgia Materiais e Mineração. 2011; 8: 80 - 85.

9 Bueno L.O. Dados de Tração a Quente e Fluência no Alumínio Comercial Puro: Parte 1: Relações entre Tensão, Taxa de Deformação, Tempo de ruptura e Temperatura. Proc. Seminário de Metais Não Ferrosos ABM 2011, 31/10-01/11,São Paulo(SP). 2010:CD ROM: 187 - 198.

10 Bueno L.O. Dados de Tração a Quente e Fluência no Alumínio Comercial Puro: Parte 2: Aplicação de diferentes Metodologias de Parametrização. Proc. Seminário de Metais Não Ferrosos ABM 2011, 31/10-01/11,São Paulo(SP). 2010:CD ROM: 199 - 211.

11 Bueno L.O. Tração a Quente e Fluência no Latão Comercial. Parte 1: Relações entre Tensão, Taxa de Deformação, Tempo de Ruptura e Temperatura. Proc. Seminário de Metais Não Ferrosos ABM 2011, 31/10-01/11,São Paulo(SP). 2010:CD ROM: 224 235.

12 Bueno LO. Tração a Quente e Fluência no Latão Comercial. Parte 2: Aplicação de diferentes Metodologias de Parametrização. Proc. Seminário de Metais Não Ferrosos ABM 2011, 31/10-01/11,São Paulo(SP). 2010:CD ROM: 236 - 247.

13 Evans RW, Wilshire B. Creep of Metals and Alloys. The Institute of Metals, London, 1985.

14 Frost HJ, Ashby MF. Deformation Mechanism Maps - The Plasticity and Creep of Metals and Ceramics, Pergamon Oxford, 1982.

15 Dieter G, Bacon D. Mechanical Metallurgy. $3^{\text {rd }}$ Edition, McGraw Hill Book Company, 1988.

16 Steen M. Creep life assessment by low strain rate tensile testing. International Journal of Pressure Vessels and Piping. 1983; 14-4: $201-225$.

17 Osgerby S, Dyson BF. Proceedings of the $5^{\text {th }}$.Intl.Conf. Creep and Fracture of Engineering Materials and Structures, Swansea. Edited by B. Wilshire and RW Evans. The Institute of Metals, London, 1993: 53-61.

18 Oh HK. Determination of rupture time and strain rate in creep by means of the uniaxial tensile test. Journal of Materials Processing Technology. 1996; 59: 294- 296.

19 Goldenberg B. A thermodynamic theory of short-term and creep rupture strength of materials. Materials Science and Engineering A. 2006; 419: 168-171.

20 Kassner, ME. Fundamentals of Creep in Metals and Alloys. Elsevier. Second Edition, Oxford, 2009.

21 Chen G, et al. High-temperature short-term tensile test and creep rupture strength prediction of the T92/TP347H dissimilar steel weld joints. Engineering Failure Analysis, 2012; 26: 220-229.

22 Sreenivasa PR. Hot-Tensile Data and Creep Properties Derived There-from for 316L(N) Stainless Steel with Various Nitrogen Contents. Procedia Engineering. 2013. 55: 82-87.

\footnotetext{
* Technical contribution to the 69th $A B M$ International Annual Congress and to the ENEMET, July 21st-25 th , 2014, São Paulo, SP, Brazil.
} 